\title{
Human capital development: a construct for underprivileged students
}

\begin{abstract}
Preparing underprivileged students to become human capital is a challenge. Issues relating to motivation and behavior are often cited as a roadblock in for quality of their learning and development. The primary goal of this study is to develop a construct as a foundation for future design and improvement to ensure successful human capital development for underprivileged students. The proposed construct is derived from the case study with Bangkok Metropolitan Administration since 2016. Observation and interviews, through the use of Big Data represent the key tasks in the study's methodology. The case study highlights many changes and improvements in science experiment and education, especially with the focus on ecology and environment. They include empathy, trust, psychological safety, participation, sense of belongingness, pride, and financial incentive (from the sales of product developed from science experiment). The proposed construct helps visualize the interrelationship among these factors. More importantly for the study's implications, recognizing the extreme value in student demographics when engaging with underprivileged students is essential for design and improvement. Finally, additional tasks are recommended to help generalize and extend this construct.
\end{abstract}




\section{Introduction}

In the past decade, many countries have commonly experienced the need for human capital development [8]. The emergence of digital technology is recognized as part of the Fourth Industrial Revolution [1]. Apparently, digital technology represents the transition into digital economy and society $[15,20]$. For social services and public service delivery, digital revolution also has immensely affected how various public agencies respond to the stakeholders' needs. There are several opportunities for the public sector to explore a new way in order to become more responsive and adaptive to the stakeholders' needs [19, 29]. These developments underline the significance of education in transforming students into human capital of a country [3]. Science education has been viewed as the key contributor to this transformation [21].

In Thailand, there are various types of schools in basic education which includes international schools, university teacher training schools (also known as demonstration and laboratory schools), public schools and private schools that are under the jurisdiction of Ministry of Education, and public schools that are part of Ministry of Interior (e.g., local municipalities, Pattaya City Administration, and Bangkok Metropolitan Administration or BMA). Students who attend public schools that are part of Ministry of Interior generally live in poverty with limited career opportunities $[12,16]$.

It is important to point out that these schools were created as part of accessibility and opportunity at the primary school level when the country experienced a rapid growth in population many decades ago. Ministry of Education could not accommodate the school's needs at that time [9]. Later, these schools were requested to offer the secondary education. Since they were not initially designed to offer the secondary-level education, there is a shortcoming in a laboratory readiness for science education

\section{Problem Background}

Quality of science education is achieved by standardized teaching and laboratory experiments $[12,16]$. In addition, there is a presumption that students in science education likely continue to study in higher education, the focus is specifically on the intensive knowledge on individual science subjects uniformly for all students. In many countries, most students perform well in science education by attending special tutorial sessions. However, for students who live in poverty with limited career opportunities, jobs after-school hours become a necessity to maintain a minimum standard of living.

Overwhelming these students with in-depth details on science subjects and payments to a special tutorial session are impractical [9]. A combination of student fatigue from work, poor quality of science laboratory, inability to attend special tutorial sessions, and lack of sense of appreciation to rigid and standardized lessons have contributed to low motivation and poor behavior. In other words, students' pain points have not been identified and engaged. This is under the notion that students come to school to learn and acquire more academic skills. 
For underprivileged students, trust become an important factor $[12,16]$. Trust is a very important issue when dealing with human capital development [25]. Social interactions at schools become minimal as the focus on a curriculum and a pedagogy emphasizes the academic excellence. Trust in teacher is also negligible due to a lack of interaction and participation in teaching and learning. Teachers often follow instructions and teaching manuals in a rigid fashion. Thus, engaging students in lesson plan development is not needed.

Without empathy, underprivileged students are viewed to be sluggish and do not illustrate the sufficient level of enthusiasm of learning. They likely give up easily on acquiring complex knowledge. In the past, more vigorous assessment and evaluation was added to ensure more discipline, motivation, and attendance through longer lecturing hours, and more intensive experiments and extra activities. Unfortunately, this has not improved the level of performance and academic achievement of underprivileged students [10].

Moreover, ongoing digital revolution has brought about the drastic change in social interactions. This widespread access to digital devices has provided a new way for social interactions but can also post the risk such as cyber bullying at schools and eventually workplaces $[12,13,26]$. Many schools (and even workplaces) are unprepared to deal with the unexpected consequences of this change (i.e., targeting their victims through digital mediums) [27]. Cyberbullying indicates the use of digital mediums to purposely harm someone on the continuous basis $[5,18]$. Underprivileged students are routinely faced with cyber bullying due to a lack of readiness by teaches and parents.

Bullying represents repeated behavior that offends, humiliates, sabotages, intimidates, or negatively affects someone's physiological and psychological well-being. Cyber bullying at schools and workplaces are about relationships, power, and control which can have negative impact on the country's human capital development [17]. It has become more serious nowadays as $19 \%$ of students, who experience cyberbullying, attempt to commit suicide [18]. This highlights a failure to encourage positive students' interactions.

For school's cyberbullying, it is defined as an aggressive and intentional act carried out by a group or individual by the electronic forms of contact which is performed repeatedly and over time against a victim who cannot readily defend him/ herself during the school years. Cyberbullying can be very dangerous and can have negative disruptions on learning and development of students since it often happens outside a school with anonymous identity of a perpetrator [22]. Emotional reactions and impacts cannot be determined. Cyberbullying at schools take place in the forms of gossip, expulsion from or exclusion of a social group, impersonation through identity theft, and constant harassment through messages and photos.

Recently, another negative consequence from the digital society is mobile addiction (which exhibits the symptoms called Problematic Internet Use and Internet Gaming Disorder). Students, who have experienced cyberbullying, likewise exhibit mobile and internet addiction [31]. To make this matter worse, by the age of 24 years old, $60 \%$ of former school bullies (those who perpetrate cyberbullying to others) can have negative impact on a company's productivity and profitability [23]. They are also expected to be convicted of a crime or a criminal act at least once [11]. Due to the fact that this bullying behavior can take place anywhere at any moment, it is extremely 
ineffective to merely address the issue by enforcement and control which are traditionally practiced.

Because of the cyberbullying seriousness, psychological safety is a basis for developing human capital [32]. This term reflects students' shared belief and feeling that they are safe for openly expressing their opinions, voicing their thoughts and concerns, and suggesting how they can perform activities together (e.g., laboratory work, experimentation, etc.). Simply, it shows that students are able to behave and speak freely without any fear of negative consequences [7]. In school environment in which psychologically safety is prevalent, students should feel accepted and respected. This feeling should enable learning and development among individuals. Psychological safety plays an important role in the success and effectiveness of the school and the workplaces. See Figure 1.

\section{[Insert Figure 1 Here]}

\section{Objectives}

The study aims to record, map, and construct a model which would incorporate all critical factors learned during pedagogical interventions for science education at BMA schools. This construct is based on integrated lesson plans and experiments that have been developed and implemented for water and soil experiments since 2016. Learning and development, especially for science education, by underprivileged students (i.e., students living in poverty) has been a challenge. Focus on contemporary practices such as empathy, psychological safety, and joy of learning represents the focus of the study, instead of more lecturing time. Furthermore, this study recognizes the extreme value in student demographics when engaging with underprivileged students.

\section{Research Methodology}

The research is an in-depth case study into two BMA school which began in 2016 . The study provides the narrative and the details from the closed observation and interaction over the period of more than three years. Joint activities and meetings with teachers, and discussions with students and their parents are applied to learn about the impacts from pedagogical improvement. The tasks on design and improvement recognize the importance of human learning. Studentcentric consideration focuses on empathy and psychology. Specific issues such as student engagement, constructive feedback, team teaching, psychological safety, and creative experiment through product development are adapted when working with underprivileged students.

The concept of Thick Data is applied to help gain the insights into the feeling, mindset, and attitude of the students. While, in general, the term Big Data (e.g., comprehensive collections of data on age, grade, family background, etc.) has become more familiarized, Thick Data deals with intensive observation and engagement on a small sample size. In this case, Thick Data helps acquire more insights into how privileged students respond to science education [30]. Thick Data 
helps gain the insights brought to the attention or understanding qualitatively (or by a series of stories) through emotion and behavior.

The observation primarily focuses on the mindset, behavior, and motivational of students. Pedagogical interventions include how to engage with students, how teachers from science subjects collaborate on experiment/ lesson plans, how to bring together external persons with suitable experiences and expertise to these experiments and lesson plans, and how to provide feedback on students' activities which are not part of formal test and examination, and how to allow open communication and learning with peers to take place. After the observation and interviews, the analysis on the findings will be made within the context of human capital development through an establishment of a construct. Literature and previous studies will be used to help add the credibility into this construct.

\section{Results and Findings}

This discussion is based on closed observation and interactions with teachers and students from 2016 until the present. Using the Thick Data concept reveals many useful findings and insights from a group of ten students and five parents as well as from two teachers. The names of the two teachers are Mr. Weeraphong Phimsarn from Matthayom Suwit Serinusorn School and Mr. Apichart Intha from Kaenthong Upatham School. Note that the names of students and parents are not to be disclosed. To begin this narrative, it is an important first step to apply empathy to learn more about students' pain points. These pain points include- a lack of spending time after school due to financial need, an inability to closely pay attention a school's lectures due to a lack of rest, and feeling of uncertainty about their future after earning a high school diploma (as many cannot afford to attend either vocational or higher education).

To start a change in a pedagogy, teachers from the science subjects (namely Physics, Chemistry, Biology, and Mathematics) initially consulted one another and decided to focus on the following premises for underprivileged students. Science experiment can be effectively conducted outside a laboratory. Science experiment should be about a solving a real (and not a hypothetical) problem that the students can relate to [10]. Product development should be an output from science experiment (not a report as traditionally practiced). Science experiment should represent an integration of science subjects instead of teaching individual subjects separately. The reason stems from the need to balance between science skills and science knowledge/ contents for students $[6,14]$

It is generally recognized that human health and ecological study have been part of science education [10]. Thus, the studies on water and soil reflect the foundation of science experiment. Often, underprivileged students have to learn about ecology and environment through textbooks without essential understanding due to a lack of proper laboratory setting and equipment. As a result, tackling polluted water and waste is chosen as a basis for students' experiment and product development. It is important to note that this step was taken with students' participation.

Due to constant concerns and complaints about bullying, conducting an experiment outside a classroom in a real-world situation should provide an opportunity for students to develop 
teamwork and to increase their interactions. In other words, being outside a classroom should allow students to know each other better. This improvement underlines the need to overcome psychological safety. Note that, due to their need to work after school, their interactions during school days have usually been minimal.

From the case study, there have been many products resulted from science experiments. For instance, water quality is expected to improve by injecting more oxygen into a surface. To prove this hypothesis, despite the fact that an instrument that would measure the oxygen level was not available, teachers and students agreed to use marigold flowers to be a quality indicator. In other words, a plot of marigold flowers is used to indicate the relationship between more oxygen and water quality. See Figure 2.

\section{[Insert Figure 2 Here]}

The second example is based on an attempt to tackle air pollution from burning dry leaves around the schools. After surveying landscape among science teachers, there is an opportunity for the students to experiment and produce the fertilizer from these dry leaves and food wastes from the school's canteen and the surrounding communities. In other words, fertilizer and vermicompost are a primary output from science experiment. Further, worms can be an indicator for the land's fertility. Once again, financial incentives play a very important role in the development of teamwork and communication, and motivation during an experiment. See Figure 3.

\section{[Insert Figure 3 Here]}

Another illustration of science experiment involves mushroom cultivation. Cultivating mushroom is a continuation from the development of fertilizer and vermicompost. This outdoor experiment is designed to help students connect with the elders who live nearby the schools. Mushroom is to be used as a common platform for students to engage and interact with the surrounding communities' elders. This mushroom cultivation initiative represents students' science learning and an attempt by teachers to improve students' community engagement. See Figures 4 and 5.

[Insert Figure 4 Here]

[Insert Figure 5 Here]

\section{Discussion and Implications}

The highlight is the use a science experiment to develop a product while tackling waste, and water and soil pollution surrounding schools and students' communities. Since the experiments are conducted outside a laboratory, this provides an opportunity for students to get to know each other better. Extra incomes earned from selling products from science experiments helps strengthen soft skills such as communication, teamwork, problem-solving, planning, entrepreneurship and financial literacy.

During this experiment, there are a number of positive developments. They include more interaction among students (which would result in more trust and willingness to discuss and 
resolve the bullying issues and mobile addiction), more appreciation and self-esteem due to an ability to design for and work on an experiment with more autonomy, and more motivation (due to daily income from selling marigold flowers).

Motivation and financial incentive are viewed as a cornerstone in science experiment. Instead of writing a report on an experiment for theorical correctness, successful product development can also reflect students' understanding and knowledge. Conducting an outdoor experiment and producing a product after school hours allow more students' interaction. This results in less reported bullying problems. School bullying, especially cyber bullying, has not been reported since the beginning of science experiments. This is likely attributed to their shared common goal.

By being outside a classroom, students feel that they can express their thoughts openly and are able to suggest any improvement on a product during an experiment without being bullied by their friends through face-to-face and social medias. Mobile addiction appears to be less due to group activities on producing the products for a market. By overcoming this concern, students can further build their self-esteem and confidence for their future development $[4,6]$

Solving a real-world problem (e.g., polluted waterway and waste) represents science education [10]. In addition, it has brought a sense of personal responsibility and belongingness among students during group work. Instead of being left behind as underprivileged and underrepresented, students feel better about themselves and believe that they could contribute to the society.

Measuring the success can be simply illustrated through national awards received by teachers and students. In 2017, experimental work on ecology and environment were nationally recognized and awarded by Crown Property Bureau Foundation and Utokapat Foundation. Both foundations are under the Royal Patronage of H.M. The King. The latest recognitions are two Outstanding Youth Awards given by National Council on Social Welfare of Thailand under Royal Patronage of H.M. The King, and Thailand's Rotary Clubs during 2018; and Outstanding School Innovativeness Award in 2019 by The Teachers' Council of Thailand. Participating teachers are chosen for the 2018 Outstanding Teacher Award by BMA's Department of Education and the 2019 Princess Maha Charki Award for Outstanding Teachers.

For the specific feedback, some of the highlights can be described as follows. First of all, from students' feedback, it is the first time that they were asked to participate in developing a lesson and an experiment plan by teachers. They were engaged more actively about their needs to help improve their academic performance instead of presuming that there were not motivated and failed to work hard during lectures and experiments. They opened up to teachers due to more trust as a result of empathy shown during the planning on a lesson and an experiment. This collaboration is the reflection of trust and is the foundation of learning and development [2].

Students also express their positive attitude towards science education. Initially, they viewed science to be a very challenging subject since many lessons from the textbooks would focus on the activities that they could not relate to. Linking science with nature and ecology helps reduce anxiety and indicate that this subject deals with daily lives (and not something that was viewed 
initially as an abstract). Having conducted an outdoor experiment has allowed students to know each other and to develop friendship which rarely happened. Students also share their positive outlook in their future as they have developed a product that can be commercially viable (due to more awareness on ecology and environment). Their future will not be restricted by only being an employee. System thinking and planning are also cited as science skills learned.

More importantly, students explicitly express the appreciation of friendship developed during the experiments. They voice their sense of belongingness in a classroom. They feel that they could provide their ideas and suggestions during product development without any fear of being made fun of or being bullied in social medias. This is part of building psychological safety in school which is essential for quality of learning and development of students.

For the five parents, they feel better when they know that their children are at schools to work with their peers instead of working as a part time employee. Their shared feedback strongly highlights better communication with the children. They point to better communication within a family. They sense that their children appear to look forward to participating in school's activities (i.e., science experiment and production). The parents feel that solving a real problem has been beneficial to their children in terms of sense of citizenship and responsibility. Despite being in an underprivileged family, the new pedagogical practices improve employability for their children.

From the viewpoints of two teachers whose background is in Chemistry and Biology respectively, a new pedagogy in science education requires a change in their mindset and roles. Becoming a facilitator for student's learning and development is a challenge when comparing with a role of a knowledge provider [14]. Understanding the pain points and building trust through more student's participation during the development of a lesson and experiment plan can overcome a lack of readiness in conducting science experiment. Anticipating the needs of students is essential. By observing the teamwork by these two teachers, students were more receptive to work together with the teaches on science experiment.

One noteworthy remark from both teachers involve a stereotype of underprivileged students by a central planner and academicians who have developed teaching guidelines and standardization. Underprivileged students are presumed to have the following characteristics: (1) lack of academic interests and inquisitive mind, and (2) need of strict supervision and control. This is not entirely a correct account as participating students in the study are proactive when given an opportunity to participate. This stereotyping issue needs be recognized before undertaking any future initiatives on science education.

\section{Contributions and Limitations}

Focusing on the development of human capital for underprivileged students reveals many critical issues. Unlike traditional students who need to excel science subjects individually, students in this case study need science skills more than knowledge (or contents). This notion highlights the need for more flexibility in learning process, especially during curriculum development and pedagogical practices $[24,28]$. 
Trusts, as a result of empathy, helps uncover several matters which have affected student's learning and development. Feeling insecure, being afraid of making a mistake, facing cyber bullying through social medias play a part in students' motivation and behavior. Not only understanding what has contributed to a lack of motivation is important, there is also a need to recognize and identify an incentive to raise the motivational level. Therefore, financial incentive is viewed to be essential in this case study. Finally, despite the abstract in nature, hope has apparently been part of positive feedback from students and parents alike. See Figure 6.

\section{[Insert Figure 6 Here]}

Due to the nature of this case study, despite a proposed model for developing privileged students as human capital, more examinations are needed to learn more about the interrelationships and the influence from the various factors. In addition, testing this proposed construct in other school locations (e.g., rural-area schools) needs to be conducted. Generalization is an important next step. Furthermore, for this construct to become effectively applicable, the impacts from critical factors such as external knowledge (e.g., expertise and skills) and outside recognition (e.g., awards and public appearance) should be further investigated. This investigation could expose how to sustain underprivileged students' positive mindset, behavior, and motivation.

\section{Conclusion}

Improving pedagogical practices for underprivileged students appears to be rely on many building blocks. First of all, commitment from science teachers to work together is crucial. Empathy shown to students by teachers is also essential. In Thailand, underprivileged students are usually faced with different issues from traditional students (who can be financially supported by their parents and who aim to attend a college or a university). Empathy shown to students is an important initial step for teachers to build.

Choosing ecology and environment as a basis for science experiment represents another critical development. This is because both teachers and students, for the first time, work together in the development of a lesson and an experiment plan. Students can think of product development based on science experiment to earn an extra income. By allowing students to work together after school to make the products, better communication and sense of belongingness in a group begin to emerge and can be sustained.

After examining several important factors, a construct (for the development of underprivileged students) which illustrates their interrelationships is formulated and proposed. This construct is part of ongoing development of human capital at schools which are faced with a great deal of diversity- school characteristics, student background, poverty, etc. The proposed constructed need to be further examined and tested for its generalizability. 


\section{$\underline{\text { References: }}$}

[1] Borgi, T., Zoghlami, N. Abed, M., and Saber, N. (2017) "Big Data for Operational Efficiency of Transport and Logistics", Proceedings for the $6^{\text {th }}$ IEEE International Conference on Advanced Logistics and Transport, July 24-27, Bali, Indonesia, pp. 165-172

[2] Brown, C. and Frame, P. Role of transitory communities of practice in business school collaborative knowledge-sharing projects: from the partner's perspective, International Journal of Innovation and Learning, 2016; 19(1): 109-124

[3] Buheji, M. Influence of visualised reflection on 'solving socio-economic problems' - a case from youth economy forums, International Journal of Innovation and Learning, 2019; 25(1): 1-16

[4] Chan, K., and Yung, B. On-site pedagogical content knowledge development, International Journal of Science Education, 2015; 37(8): 1246-1278

[5] Choon, H. and Wong, D. (2016) Traditional school bullying and cyberbullying perpetration: examining the psychosocial characteristics of Hong Kong male and female adolescents, Youth and Society, 2016; 51(1): 3-29

[6] Deep, S., Salleh, B., and Othman, H. Study on problem-based learning towards improving soft skills of students in effective communication class, International Journal of Innovation and Learning, 2019; 25(1): 17- 34

[7] Edmondson, A and Lei, Z. Psychological safety: the history, renaissance, and future of an interpersonal construct, Annual Review of Organizational Psychology and Organizational Behavior, 2014; 1(1): 23-43

[8] Espinel, V. The digital economy: what is it and how will it transform our lives, 2016 [cited 2019 August 12] available from https://www.weforum.org/agenda/2016/11/the-digital-economy-whatis-it-and-how-will-it-transform-our-lives/

[9] Faikhamta, C. Fifth year pre-service science teachers' struggles with and learning about teaching science through a-year-long field experience. Kasetsart Journal (Social Science), 2011; 32(1): 140-147

[10] Faikhamta, C., and Clarke, A. Science student teachers' struggles with and learning about classroom action research during their field experiences, Asia-Pacific Journal of Education, 2015; 35(2): 259-273

[11] Feldscher, K. For both bullies and their victims, victimization plays a role, 2012 [cited 2016 December 5] available from https://www.hsph.harvard.edu/news/features/holt-bullying/

[12] Fry, G. and $\mathrm{Bi}, \mathrm{H}$. The evolution of educational reform in Thailand: the Thai educational paradox, Journal of Educational Administration, 2013; 51(3): 290-319 
[13] Gangadharan, S. The downside of digital inclusion: expectations and experiences of privacy and surveillance among marginal internet users, New Media and Society. 2015 November [cited 2018 October 26]; 19(4): 597-615. Available from http://eprints.Ise.ac.uk/64156/1/Downside_digital_inclusion.pdf

[14] Guerriero, S. Teachers' pedagogical knowledge and the changing of nature of teaching profession. Paris: OECD Publishing; 2017

[15] Gyurkovics, J. and Vas, Z. Knowledge sourcing in a traditional industry: prospects of peripheral regions, International Journal of Innovation and Learning, 2018; 24(2): 220 - 237

[16] Hallinger, P. and Bryant, D. Synthesis of findings from 15 years of educational reform in Thailand: lessons on leading educational change in East Asia, International Journal of Leadership in Education, 2013; 16(4): 399-418

[17] Heatherington, W. and Coyne, I. Understanding individual experiences of cyberbullying encountered through work, International Journal of Organization Theory \& Behavior, 2017; 17(2): 163-192

[18] Kuja, M. Cyber-bullying: the new violence against women by women, 2016 [cited 2017 May 5] available from https://www.worldpulse.com/community/users/kujamac12/posts/65258

[19] Lanier, P., Credo, K., and Matherne III, C. Increased millennial engagement through servicelearning: the causal impact of community service self-efficacy, International Journal of Innovation and Learning, 2017; 22(4): 424 - 433

[20] Liu, X. Business model transformation in digital enablement context through frugal innovation: learning from Chinese experience, International Journal of Technology Policy and Management, 2017; 17(4): 36-375

[21] Lopez-Leyva, S. and Rhoades, G. Country competitiveness relationship with higher education indicators", Journal of Technology Management \& Innovation, 2016; 11(4): 47-55

[22] Manna, R., Calzone, S., Adinolfi, P. and Palumbo, R. School bullying as a quality issue in educational institutions, The TQM Journal, 2019; 31(2): 274-291

[23] Mesch, G. Parental Mediation, Online Activities, and Cyberbullying, Cyber Psychology and Behavior, 2009; 12(4): 387- 393

[24] O'Riordan, F. Transformational pedagogy through curriculum development discourse, International Journal of Innovation and Learning, 2018; 23(2): 244-260

[25] Rafiq, M. and Wu, W. Managerial trust outlook in China and Pakistan, Human Systems Management, 2017; 36(4): 363-368 
[26] Ropret, M., Aristovnik, A., Klun, M. and Stare, J. The importance of HRM factors for public sector innovativeness in Eastern Europe, International Journal of Innovation and Learning, 2017; 22(4): $480-497$

[27] Sezer, B., Yilmaz, R. and Karaoglan Yilmaz, F. Cyber bullying and teachers' awareness, Internet Research, 2015; 25(4): 674-687

[28] Soraya, D. and Moustaghfir, K. International faculty, knowledge transfer, and innovation in higher education: A human resource development perspective, Human Systems Management, 2019; 38(4): 423-431

[29] Wirtz, B. and Birkmeyer, S. Open government: origin, development, and conceptual perspectives, International Journal of Public Administration, 2015; 38(5): 381-396

[30] Wright, M. How Thick Data Helps You Build Emotional Connections With Customers, 2018 [cited 2019 July 19] available from https://www.cmswire.com/customer-experience/how-thickdata-helps-you-build-emotional-connections-with-customers/

[31] Xue, Y., Dong, Y., Luo, M., Mo, D., Dong, W., Zhang, Z. and Liang, H. Investigating the impact of mobile SNS addiction on individual's self-rated health, Internet Research, 2018; 28(2): 278-292

[32] Yanchus, N., Derickson, R., C. Moore, S., Bologna, D. and Osatuke, K. Communication and psychological safety in veteran's health administration work environments, Journal of Health Organization and Management, 2014; 28(6): 754-776 


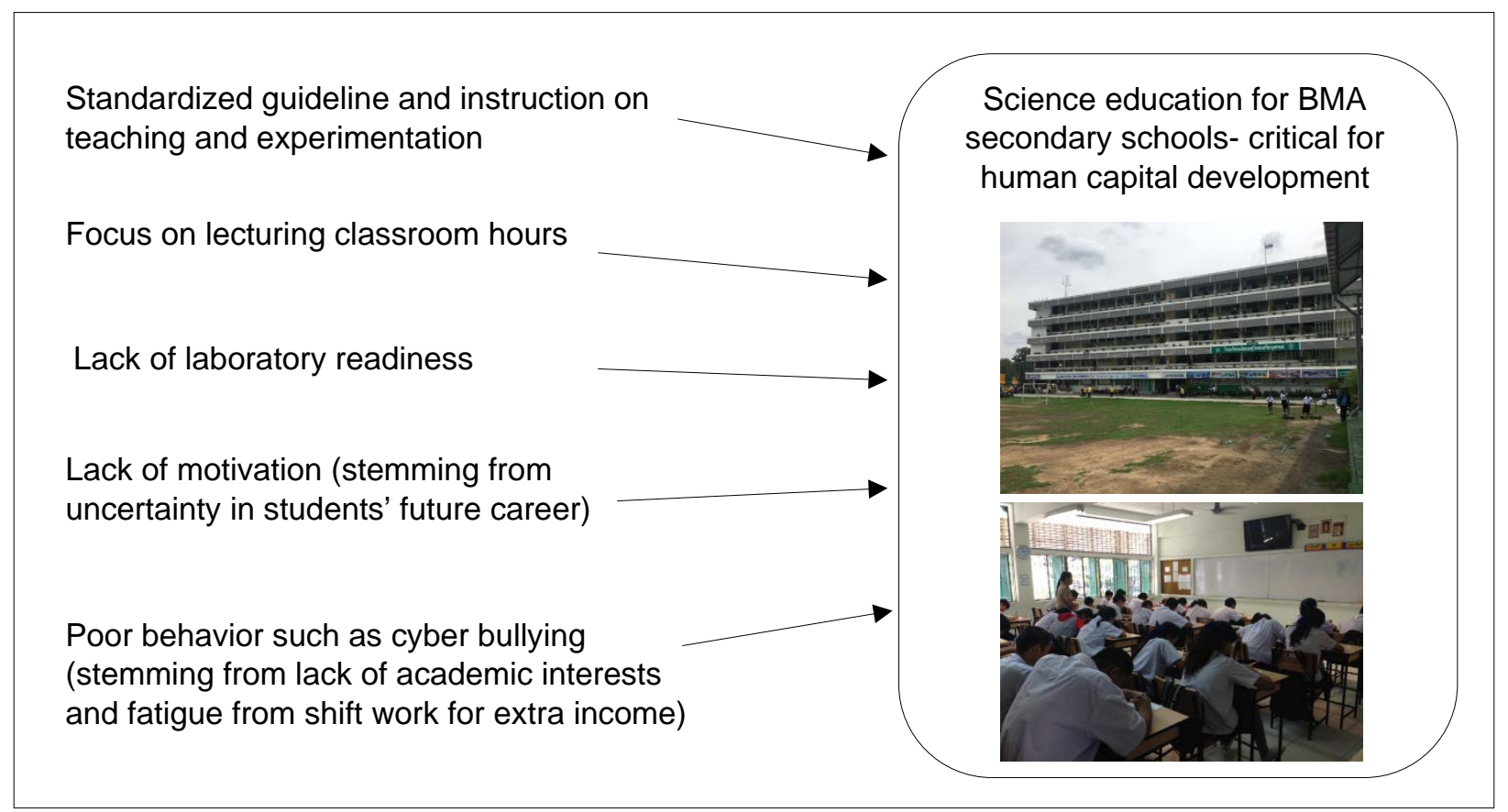

Figure 1: Illustration of the Problems facing Quality of Learning and Development
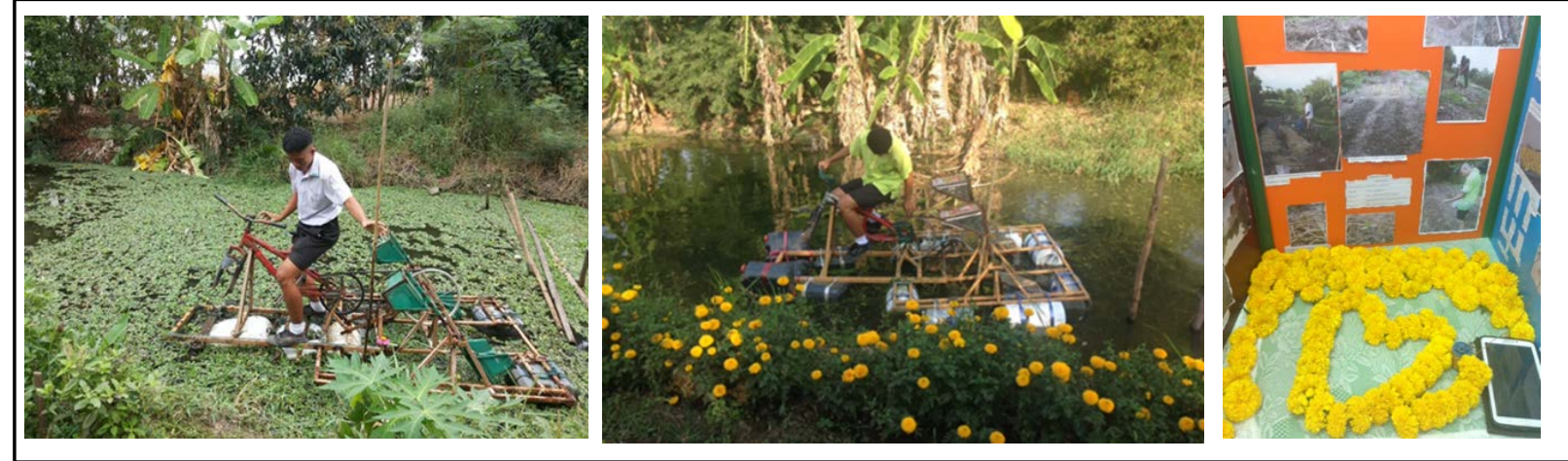

Figure 2: Integrating Physics, Chemistry, and Biology in Science Experiment When Dealing with Water Pollution and Marigold Flowers 


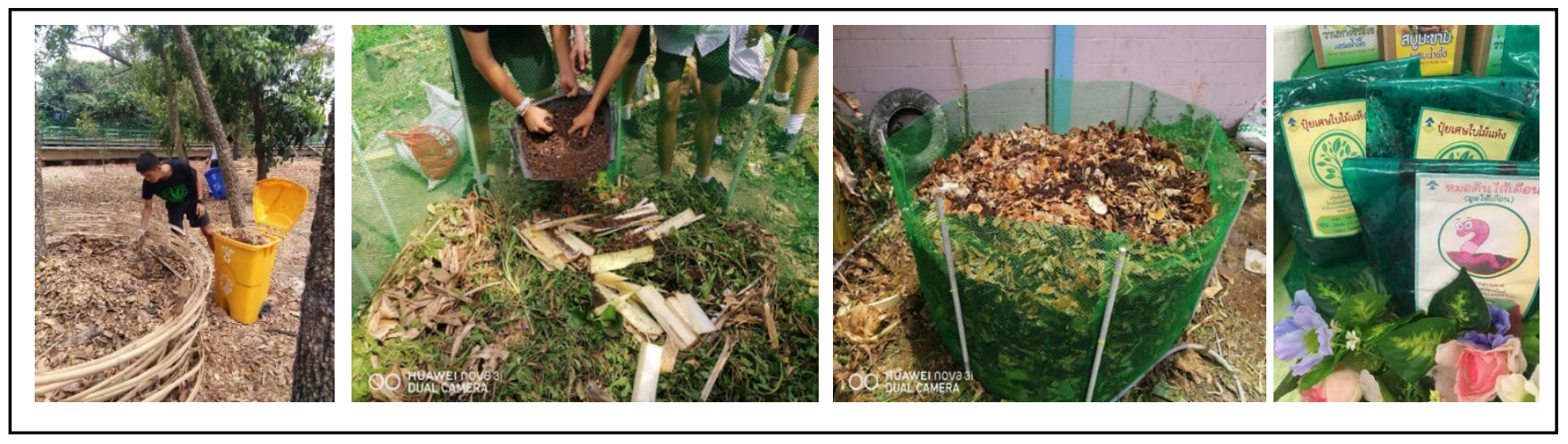

Figure 3: Science Experiment Dealing with Waste, and Fertilizer and Vermicompost Products

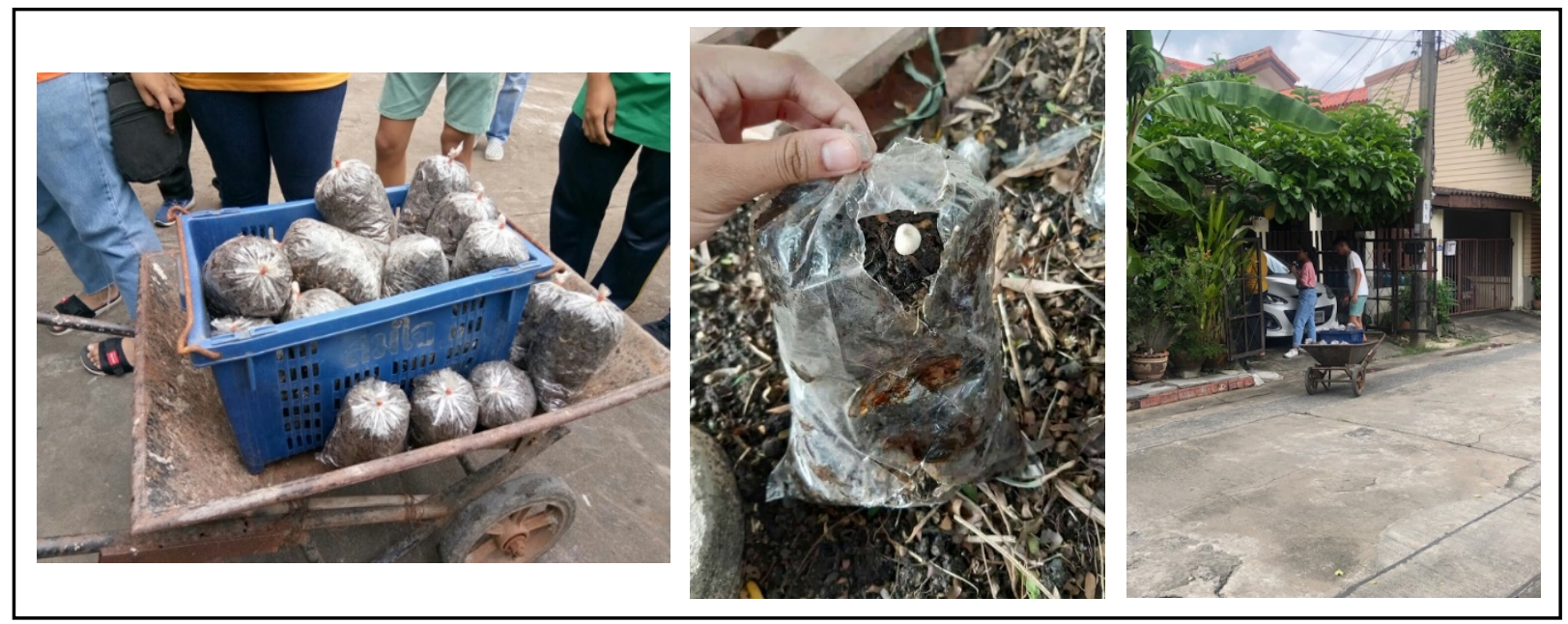

Figure 4: Science Experiment with Mushroom Cultivation and Community Engagement

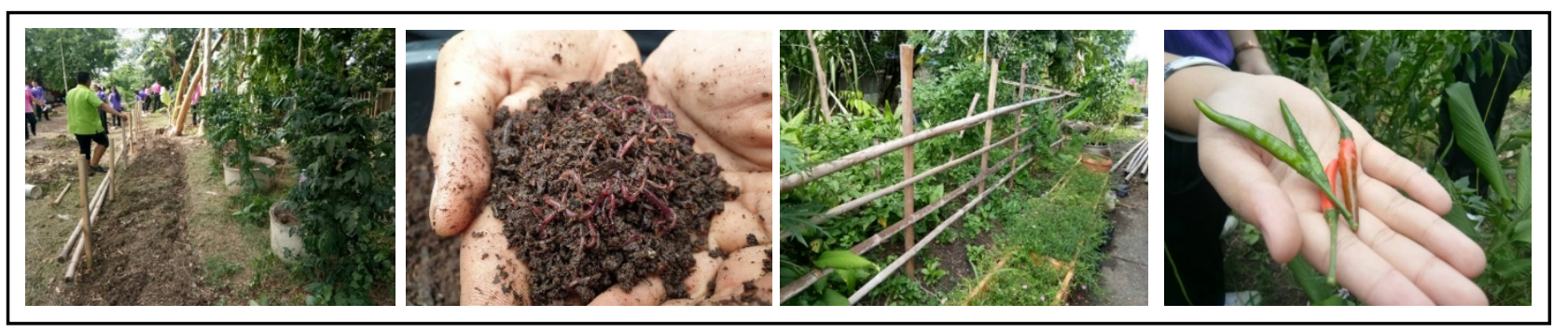

Figure 5: Science Experiments from Testing Various Types of Fertilizers and Vermicompost 


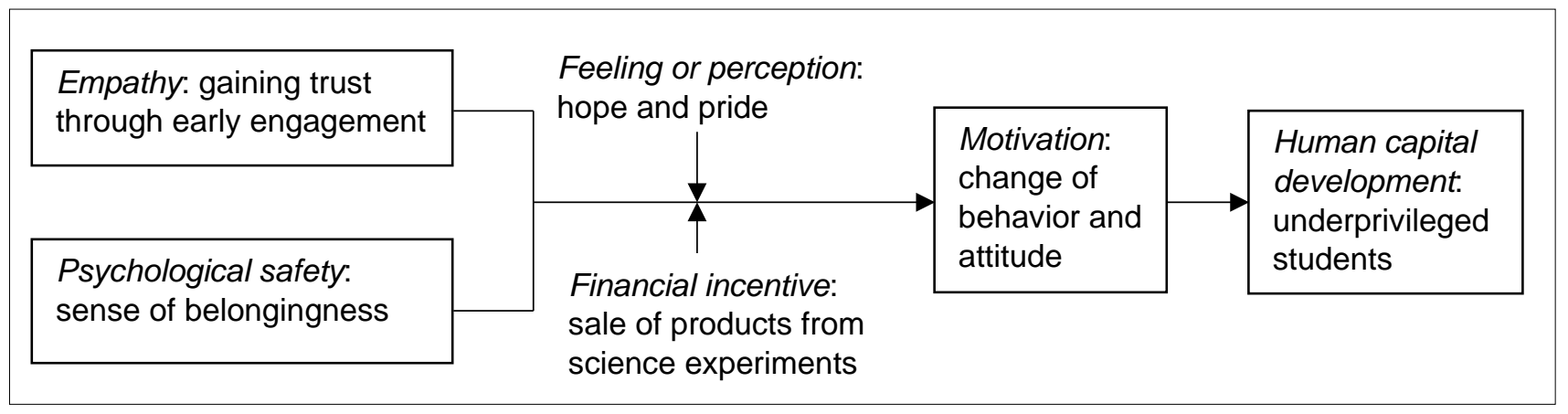

Figure 6: Proposed Construct Learned from the Case Study on Human Capital Development 